\title{
Otimização do uso da água em sistemas de irrigação por aspersão
}

\author{
Vital P. da S. Paz ${ }^{1}$, José A. Frizzone ${ }^{2}$, Tarlei A. Botrel² \& Marcos V. Folegatti² \\ ${ }^{1}$ Escola de Agronomia da Universidade Federal da Bahia, CEP 44380-000, Cruz das Almas, BA. Fone: (75) 621-1220. \\ E-mal:vpspaz@ufba.br (Foto) \\ ${ }^{2}$ Escola Superior de Agricultura "Luiz de Queiroz"/USP. CP 9, CEP 13418-900, Piracicaba, SP. Fone: (19) 3429-4217. \\ E-mail: frizzone@carpa.ciagri.usp.br e mvfolega@carpa.usp.br
}

Protocolo $89-19 / 6 / 2001$

\begin{abstract}
Resumo: O manejo adequado de um sistema de irrigação deverá ser capaz de propiciar ao agricultor o uso eficiente da água, para aumentar a produtividade das culturas, reduzir os custos de produção e, conseqüentemente, maximizar o retorno dos investimentos. Técnicas eficientes de aplicação de água constituem condições essenciais para o desenvolvimento agrícola sustentado, baseado na economia do recurso hídrico e na preservação ambiental. O objetivo deste trabalho foi estudar a redução da receita líquida decorrente da aplicação deficiente ou excessiva de água, a influência da uniformidade de distribuição de água sobre a lâmina ótima econômica que maximiza a receita líquida e prever a operação otimizada de sistemas de irrigação por aspersão. A minimização das perdas econômicas, ou redução da receita líquida, está relacionada à uniformidade de distribuição de água pelo sistema, ao preço do produto e ao custo da irrigação. Sistemas de irrigação que não apresentam boa uniformidade de distribuição de água não são apropriados quando o objetivo é o máximo retorno econômico. A operação ótima dos sistemas de irrigação baseada nas estratégias de otimização econômica para maximização da receita líquida, proporciona níveis adequados de eficiência de aplicação, eficiência de armazenamento e área adequadamente irrigada. A uniformidade de distribuição, o custo da água e o valor pago pelo produto, são fatores determinantes para a otimização de sistemas de irrigação, quando o objetivo é a maximização da receita líquida e a economia do recurso hídrico.
\end{abstract}

Palavras-chave: eficiência de uso da água, otimização, irrigação por aspersão

\section{Optimization of water use in sprinkler irrigation systems}

\begin{abstract}
Efficient water use can be achieved by appropriate water management. This leads to higher yield, reduced production costs and ultimately, maximum investment returns. Furthermore, the use of efficient water management and application techniques are essential for sustainable agricultural development and a rational use of the natural resources. The purpose of the present investigation was to evaluate the reduction of the net revenue due to deficient or excessive water application. Determining the effects of uniformity of water distribution on the irrigation depth that maximizes returns and providing the necessary information to optimize the operation of sprinkler irrigation systems were also part of the objectives. The results show that minimization of revenue losses depends on the uniformity of water distribution of the irrigation system, the commodity price and the irrigation costs. Hence, irrigation systems with uneven water distribution are not appropriate for maximization of economic returns. The best operation of irrigation systems, determined from optimization strategies to maximize net profits, consisted of improved water application efficiency, high water storage efficiency and the area being adequately irrigated. When maximization of net revenue is the objective function, the uniformity of water distribution, the cost of the applied water and the commodity price are the decisive factors for the optimization of irrigation systems.
\end{abstract}

Key words: efficient water use, optimization, sprinkler irrigation systems

\section{INTRODUÇÃO}

Estimativas mais precisas da produção a partir da combinação dos recursos disponíveis têm sido objeto de vários estudos nos últimos anos. Dentre os fatores de produção, a água e os nutrientes são os que limitam os rendimentos com maior freqüência; assim, o controle da irrigação e da fertilidade do solo constituem critério essencial para o êxito da agricultura (Frizzone, 1993). Seja em regiões áridas ou semiáridas, onde a água é escassa, e também em regiões úmidas, a otimização da produção depende da utilização racional do recurso hídrico. 
Como a disponibilidade de água de boa qualidade é vital para as futuras gerações e a irrigação tem provocado alterações no meio ambiente difíceis de serem previstas, é fundamental que se estabeleçam padrões claros para a avaliação do impacto ambiental resultante da irrigação, a fim de um crescimento sem os problemas constatados em alguns projetos em funcionamento. As fases de planejamento e dimensionamento do projeto são os momentos mais adequados para se diagnosticar os possíveis impactos ambientais resultantes da irrigação e realizar os ajustes necessários, de modo que os possíveis efeitos adversos da irrigação, oriundos da implementação do projeto, sejam minimizados (Bernardo, 1997).

A aplicação da água por sistemas de irrigação não é perfeitamente uniforme. Para um método de irrigação, em particular, elevada uniformidade pode ser alcançada, ocorrendo, no entanto, um aumento dos custos de operação. É comum expressar-se a uniformidade de distribuição de água de um sistema de irrigação por meio de um coeficiente de uniformidade que expressa a variabilidade da lâmina de irrigação aplicada sobre o solo (Solomon, 1984). Christiansen (1942) foi o primeiro pesquisador a propor um coeficiente para caracterizar a uniformidade de distribuição de água em sistemas de irrigação. A literatura, em geral, cita um valor médio recomendável de $80 \%$ para a uniformidade em sistemas de irrigação por aspersão. Um aspecto a ser considerado é a uniformidade da umidade abaixo da superfície do solo. Paiva (1980) e Rezende et al. (1993) analisaram o efeito da uniformidade de distribuição da água na superfície do solo sobre a redistribuição desta no perfil, e verificaram aumento dos coeficientes de uniformidade ao longo do tempo, em todas as profundidades estudadas.

Assumindo-se que um sistema de irrigação aplica água segundo um modelo teórico de distribuição, existe uma lâmina ótima que deve ser infiltrada, de forma a minimizar a redução da receita líquida esperada, causada pelo excesso e/ou pelo déficit de água na área. A esta lâmina denominou-se lâmina ótima de irrigação, ou seja, é a lâmina média de água que deve ser infiltrada no solo para proporcionar a máxima receita líquida, minimizando a redução da receita causada pelo excesso e/ou déficit de água (Norum et al., 1979; Peri et al., 1979).

Paz et al. (1997) estudaram a redução da receita líquida decorrente do déficit e do excesso de água aplicada, considerando o custo da água, o preço do produto e a uniformidade de distribuição do sistema de irrigação, a partir das metodologias apresentadas por Norun et al. (1979), Peri et al. (1979) e English (1990). Os autores concluíram, ainda, que a irrigação com maior uniformidade proporciona melhores resultados econômicos em qualquer combinação de preço do produto e custo da água.

Os objetivos deste trabalho foram estudar a influência do custo da água e do preço do produto sobre a lâmina ótima econômica, o efeito da uniformidade de distribuição de água sobre o déficit e o excesso de água aplicada, além de prever a operação otimizada de sistemas de irrigação por aspersão.

\section{MATERIAL E MÉTODOS}

Utilizou-se o coeficiente de uniformidade de Christiansen (1942) para representar a distribuição da água do sistema de irrigação. A análise econômica da receita líquida obtida com a cultura de feijão (Phaseolus vulgaris, L) foi feita utilizando-se a metodologia apresentada por English (1990). Considerou-se a função de resposta do feijoeiro, cultivar carioca, determinada por Frizzone (1986) nas condições climáticas de Ilha Solteira (SP) e válida no intervalo de 105 a $621 \mathrm{~mm}$ de lâmina total de água aplicada (Eq. 1). A máxima produção de grãos estimada é $2432 \mathrm{~kg} \mathrm{ha}^{-1}$ com lâmina total de água de 527,7 mm:

$$
\mathrm{Y}(\mathrm{W})=63,9656+8,9745 \mathrm{~W}-0,008503 \mathrm{~W}^{2}
$$

em que:

$\mathrm{Y}(\mathrm{W})$ - produção esperada da cultura, $\mathrm{kg} \mathrm{ha}^{-1}$

W - lâmina total de água aplicada, $\mathrm{mm}$

Sendo $\mathrm{P}_{\mathrm{i}}$ o preço pago por unidade produzida, a receita líquida (IL) por unidade de área é:

$$
\mathrm{IL}(\mathrm{W})=\mathrm{Y}(\mathrm{W}) \mathrm{P}_{\mathrm{i}}-\mathrm{C}(\mathrm{W})
$$

em que $C(W)$ representa o custo de produção da cultura irrigada, por unidade de área.

O custo de produção da cultura irrigada foi considerado função linear (Hart et al., 1980):

$$
\mathrm{C}(\mathrm{W})=\mathrm{C}_{\mathrm{o}}+\mathrm{C}_{\mathrm{w}} \mathrm{W}
$$

em que:

$\mathrm{C}_{0}$ - custo de produção por unidade de área da cultura irrigada, não relacionado à aplicação de água de irrigação

$\mathrm{C}_{\mathrm{w}}$ - custo de produção por unidade de área da cultura irrigada, por unidade de volume de água aplicada

O custo da água $\left(\mathrm{C}_{\mathrm{w}}\right)$ para a cultura de feijão apresentou variação de US\$ 0,32 a $0,75 \mathrm{~mm}^{-1}$ ha $^{-1}$ (IPT,1994). O preço do produto $\left(\mathrm{P}_{\mathrm{i}}\right)$ variou de US\$ 0,44 a 1,62 kg-1 (Preços Agrícolas, 1994). O custo de produção da cultura irrigada, não associado à aplicação de água de irrigação $\left(\mathrm{C}_{\mathrm{o}}\right)$, foi considerado igual a US\$ 410,88 ha-1 (IPT, 1994).

Sendo a disponibilidade de terra o fator limitante à produção, existe uma quantidade ótima de água fornecida à cultura que proporciona a máxima receita líquida (English, 1990), dada pela expressão:

$$
\mathrm{W}_{1}^{*}=\frac{\mathrm{C}_{\mathrm{w}}-\mathrm{P}_{\mathrm{i}} \mathrm{B}}{2 \mathrm{P}_{\mathrm{i}} \mathrm{C}}
$$

em que:

$\mathrm{W}_{1}{ }^{*}$ - lâmina de água necessária para obter a máxima receita líquida quando a disponibilidade de terra é o fator limitante à produção, $\mathrm{mm}$

B,C - coeficientes da função de produção $(\mathrm{Y}(\mathrm{W})=\mathrm{A}+$ $\mathrm{B} \mathrm{W}+\mathrm{C} \mathrm{W}^{2}$ )

Para estimativa e análise da perda econômica devida ao déficit ou ao excesso de água aplicada considera-se que: 
a) o sistema de irrigação aplica a lâmina total de água em cada ponto ao longo da área irrigada, tendo-se, assim, uma distribuição dessas lâminas (cada ponto representa uma parcela da área total irrigada pelo sistema);

b) em cada ponto da área irrigada pelo sistema, conhecida a quantidade total de água aplicada no ciclo da cultura, estimase uma receita líquida;

c) supondo-se uniforme a distribuição de água em toda a área, sob o sistema, tem-se uma receita líquida total ótima, proporcionada por uma lâmina ótima econômica de irrigação $\left(\mathrm{W}^{*}\right)$;

d) a perda econômica em cada ponto i da área, sob o sistema, é estimada pela diferença entre receita líquida total obtida com a aplicação da lâmina total ótima econômica, $\mathrm{W}^{*}$, e a receita líquida total no ponto, obtida com a correspondente lâmina total aplicada $\left(\mathrm{W}_{\mathrm{i}}\right)$, ou seja:

$$
\Delta \mathrm{EC}_{\mathrm{i}}=\mathrm{IL}^{*}-\mathrm{IL}_{\mathrm{i}}
$$

em que:

$\Delta \mathrm{EC}_{\mathrm{i}}$ - perda econômica no ponto $\mathrm{i}$, ao longo da área irrigada, US\$

IL - receita líquida ótima obtida com a lâmina total ótima $\mathrm{W}^{*}, \mathrm{US} \$$

$\mathrm{IL}_{\mathrm{i}}$ - receita líquida no ponto $\mathrm{i}$, obtida com a lâmina $\mathrm{W}_{\mathrm{i}}$, US\$

A perda econômica em cada ponto pode ser devida ao excesso ou ao déficit de água. Há déficit quando a lâmina total aplicada no ponto é menor que a lâmina ótima e há excesso quando a lâmina total aplicada no ponto é maior que a lâmina total ótima de irrigação.

Considerando-se que as lâminas de água aplicadas têm distribuição normal, as reduções de receita líquida causadas pelo excesso $(\alpha)$ e pelo déficit ( $\beta$ ) de água foram estimadas de acordo com Paz (1995).

Para análise da operação do sistema de irrigação foram utilizados os parâmetros de eficiência, que expressam a qualidade da irrigação, de acordo com Walker (1979).

\section{RESULTADOS E DISCUSSÃO}

A lâmina de água ótima econômica aumenta quando o valor pago pelo produto também aumenta. Maiores lâminas estão relacionadas a baixos custos da água; portanto, a quantidade de água necessária para maximização da receita líquida diminui quando o seu custo é alto e, quando a cultura tem elevado valor econômico, a lâmina ótima econômica de irrigação é menos influenciada pelo custo da água (Fig. 1).

A lâmina ótima econômica aproxima-se da quantidade de água para máxima produção à medida em que o seu custo é reduzido e o valor pago pelo produto aumenta; se o custo da água é elevado, a lâmina que proporciona o rendimento ótimo diminui (Fig. 1). Observou-se uma economia de água de até 18,64\% em relação à lâmina para máxima produção, em função do custo da água e do preço do produto.

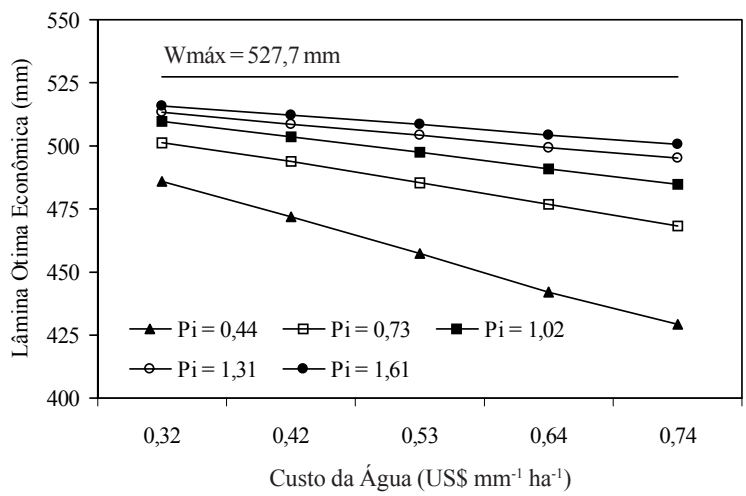

Figura 1. Lâmina de água ótima econômica em função do custo da água, para diferentes preços do produto $(\mathrm{Pi})$

A relação entre a redução da receita líquida pelo déficit e a redução da receita líquida pelo excesso $(\beta / \alpha)$ expressa o efeito do déficit sobre o excesso de água. No presente trabalho, para a função de resposta da cultura à irrigação e para os valores de custo da água e preço do produto analisados, o efeito do déficit foi sempre superior ao efeito do excesso na redução da receita líquida $(\beta / \alpha>1)$. O efeito relativo do déficit sobre o excesso $(\beta / \alpha)$ diminui com o aumento do custo da água. Para determinada uniformidade, observa-se que a relação $\beta / \alpha$ aumenta a medida em que o custo da água diminui, mesmo que a cultura apresente elevado valor econômico (Fig. 2A e B). Para qualquer combinação de custo da água e preço do produto, a relação $\beta / \alpha$ aumenta quando o sistema apresenta baixa uniformidade (Fig. 2B). A uniformidade de distribuição de um sistema deve ser melhorada se a cultura tem elevado valor econômico, mesmo para baixo custo da água; o que se traduz em economia de
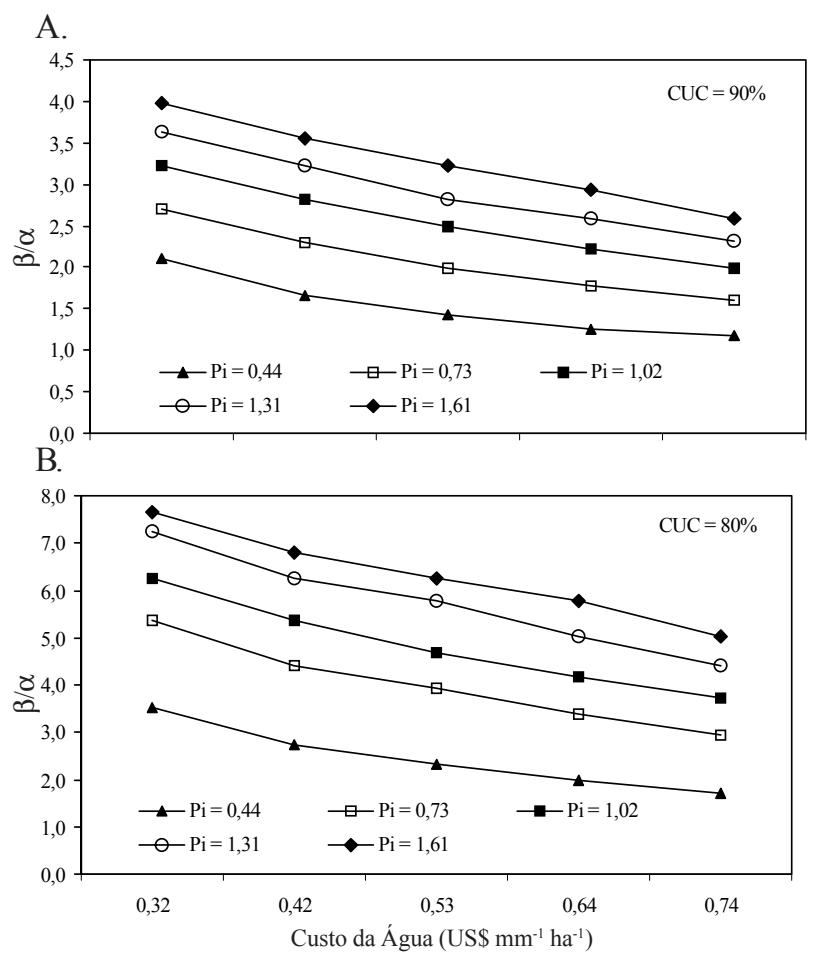

Figura 2. Efeito relativo do déficit sobre o excesso de água aplicada $(\beta / \alpha)$, para diferentes custos da água e preços do produto em sistemas de irrigação com uniformidade de distribuição de (A) $90 \%$ e (B) $80 \%$ 
água, visto que ocorrerá equilíbrio entre o volume aplicado em excesso e o déficit que ocorre na outra fração da área.

Para um nível ótimo econômico de exploração da cultura e se considerando um cenário de custo da água e preço do produto, definiu-se uma lâmina ótima relativa, ou seja, em relação a dado requerimento $\left(\mathrm{X}_{\mathrm{r}}^{*}\right)$, qual deverá ser a lâmina média aplicada pelo sistema de irrigação $\left(\mathrm{X}_{\mathrm{m}}\right)$ para atender a este requerimento, de forma a tornar mínima a redução da receita líquida devida ao déficit e ao excesso de água? Os sistemas que aplicam água uniformemente mostram-se mais apropriados para atender ao requerimento da cultura, resultando na aplicação de uma menor lâmina média ótima econômica.

Neste trabalho, com $\beta / \alpha$ igual a 3,93 e um sistema com uniformidade de $90 \%$, para atender a um requerimento de 12 mm, o sistema deve aplicar uma lâmina média ótima de 13,3 mm, ou seja, 10,8\% superior à lâmina requerida (Fig. 3A). Peri et al. (1979) encontraram, para $\beta / \alpha$ igual a 4 , uma lâmina média $10 \%$ superior ao requerimento. Para a mesma situação e com uniformidade de $80 \%$, o sistema deve aplicar uma lâmina média de $14,9 \mathrm{~mm}$ para atender ao requerimento, portanto, $24,10 \%$ superior a esse (Fig. 3B).

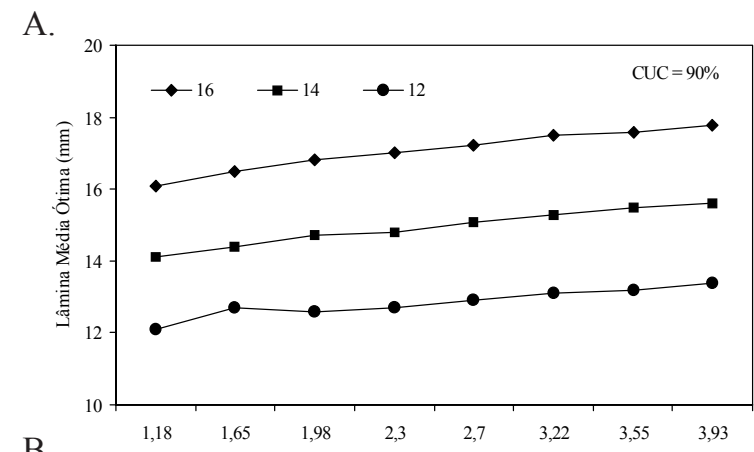

B.

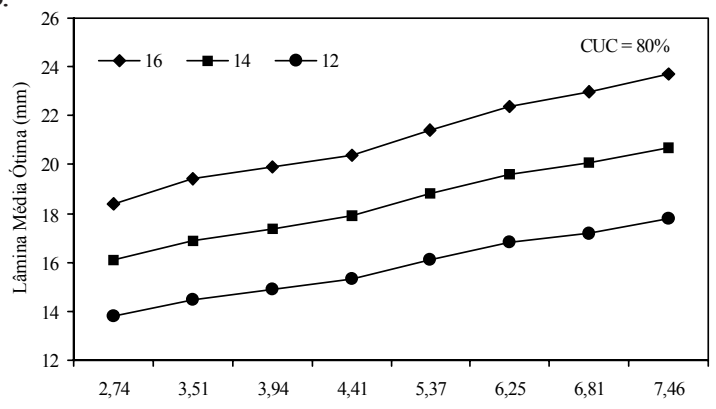

Figura 3. Lâmina média ótima em função de $\beta / \alpha$, para requerimentos de 12,14 e $16 \mathrm{~mm}$ e uniformidade de distribuição de água de $90 \%$ (A) e $80 \%$ (B)

O decréscimo da uniformidade resulta no aumento de $\beta / \alpha$, visto que proporciona maiores áreas de déficit e de excesso, acarretando aumento da lâmina ótima para atender a um requerimento, o que pode ser visto na Figura 3 (A e B).

Avaliou-se a operação do sistema de irrigação em função da uniformidade de distribuição. A qualidade da irrigação, avaliada pelos parâmetros de eficiência, reduz-se à medida que a uniformidade de distribuição diminui (Fig. 4A e B) para qualquer cenário ótimo econômico de exploração da cultura.

Quanto menor a lâmina média ótima relativa $\left(\mathrm{X}_{\mathrm{m}} / \mathrm{X}_{\mathrm{r}}^{*}\right)$, indicando que se o sistema atende um requerimento próximo
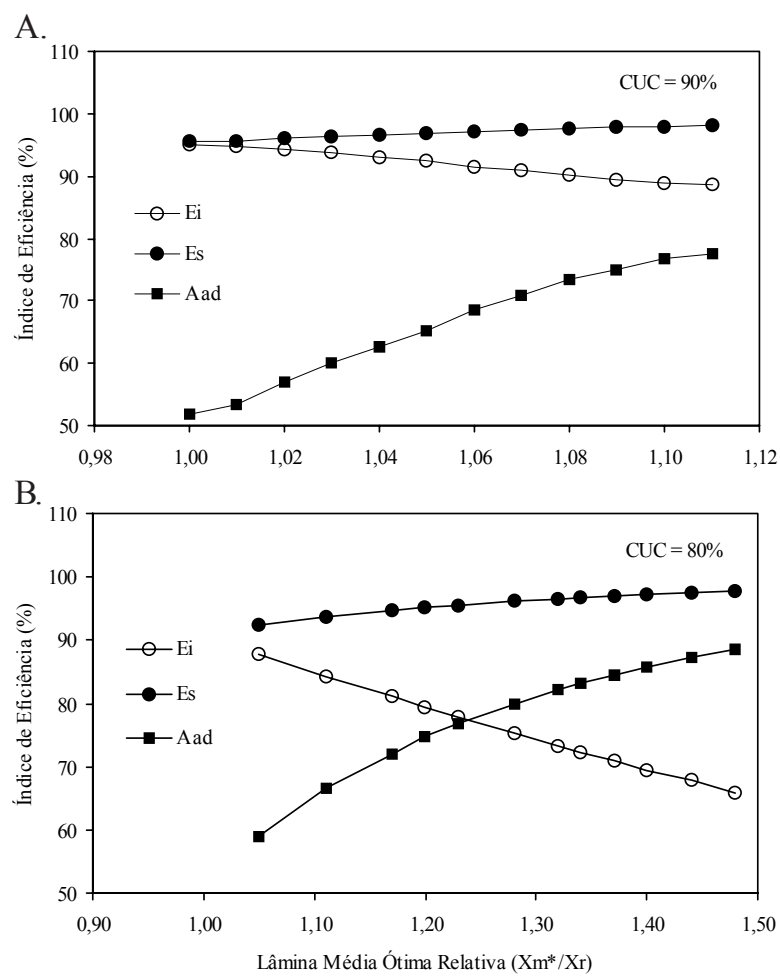

Figura 4. Eficiência de irrigação (Ei), eficiência de armazenamento (Es) e área adequadamente irrigada (Aad) para a operação ótima do sistema de irrigação, com uniformidade de distribuição de água de 90\% (A) e 80\% (B)

da lâmina média aplicada, maior será a eficiência de aplicação, porém, a qualidade da irrigação fica comprometida pela diminuição da eficiência de armazenamento e conseqüente redução da área adequadamente irrigada. Este fato se torna mais acentuado se o sistema apresenta baixa uniformidade de distribuição de água (Fig. 4B).

Para um cenário de exploração econômica da cultura em que o efeito relativo do déficit sobre o excesso é conhecido e o sistema de irrigação apresenta uma dada uniformidade de distribuição, é possível se estabelecer a operação otimizada do sistema de irrigação, minimizando os efeitos do déficit e do excesso de água aplicada, e, portanto, reduzindo possíveis perdas de água.

\section{CONCLUSÕES}

1. A minimização da redução da receita líquida está relacionada à uniformidade de distribuição de água pelo sistema, ao preço do produto e ao custo da irrigação.

2. A operação ótima dos sistemas de irrigação, baseada nas estratégias de otimização econômica para maximização da receita líquida, proporciona níveis adequados de eficiência de aplicação, eficiência de armazenamento e área adequadamente irrigada, em condições de boa uniformidade de distribuição de água.

3. A uniformidade de distribuição, o custo da água e o valor pago pelo produto são fatores determinantes para a otimização de sistemas de irrigação, quando o objetivo é a maximização da receita líquida e a economia do recurso hídrico. 


\section{AGRADECIMENTOS}

Agradecimentos à Fundação de Amparo à Pesquisa do Estado - FAPESP, pela concessão da bolsa de estudo para o Programa de Pós-Doutoramento, e à Escola Superior de Agricultura "Luiz de Queiroz", pelo irrestrito apoio.

\section{LITERATURA CITADA}

Bernardo, S. Impacto ambiental da irrigação no Brasil. In: Silva, D.D. da; Pruski, F.F. (ed.). Recursos hídricos e desenvolvimento sustentável da agricultura. Viçosa: MMA, SRH, ABEAS, UFV, 1997.252p.

Christiansen, J.E. Irrigation by sprinkler. Berkeley: California Agricultural Station. 1942, 124p. Bulletin, 670

English, M.J. Deficit irrigation. I: Analytical framework. Journal of the Irrigation and Drainage Division of ASCE, New York, v.116, n.3, p.399-412, 1990.

Frizzone, J.A. Funções de resposta do feijoeiro (Phaseolus vulgaris, L.) ao uso de nitrogênio e lâminas de irrigação. Piracicaba: ESALQ, 1986. 133p. Tese Doutorado

Frizzone, J.A. Funções de resposta das culturas à irrigação. Piracicaba: ESALQ/DER, 1993.53p. Série Didática 6

Hart, W.E.; Norum, D.I.; Peri,G. Optimal seasonal irrigation application analysis. Journal of the Irrigation and Drainage Division of ASCE, New York, v.106, n.3, p.221-235, 1980.

IPT - Instituto de Pesquisa Tecnológico. Relatórios técnicos. São Paulo, 1994, 27p.
Norum, D.I.; Peri, G.; Hart, W.E. Application of systems optimal depth concept. Journal of the Irrigation and Drainage Division of ASCE, New York, v.105, n.4, p.357-367, 1979.

Paiva, J.B.D. de. Uniformidade de aplicação de água abaixo da superfície do solo, utilizando-se irrigação por aspersão. São Carlos: EESC/USP, 1980.333p. Tese Doutorado

Paz, V.P.S. Condições ótimas de operação de sistemas de irrigação por aspersão. Piracicaba: ESALQ, 1995.125p. Tese Doutorado

Paz, V.P.S.; Frizzone, J.A.; Botrel, T.A.; Folegatti, M.V. Redução da receita líquida por déficit ou excesso de água na cultura do feijoeiro. Pesquisa Agropecuária Brasileira, Brasília, v.32, n.9, p.869-75, 1997.

Peri, G.; Hart, W.E.; Norum, D.I. Optimal irrigation depths - A method of analysis. Journal of the Irrigation and Drainage Division of ASCE, New York, v.105, n.4, p.341-354, 1979.

Preços Agrícolas. Fundação de Estudos Agrário Luiz de Queiroz/ESALQ, Piracicaba, n.8, p.10-52, 1994.

Rezende, R.; Frizzone, J.A.; Botrel, T.A. Desempenho de um sistema de irrigação pivô central quanto à uniformidade de distribuição de água abaixo e acima da superfície do solo. Engenharia na Agricultura, Série Irrigação e Drenagem, Viçosa, v.1, n.1, p.1-7, 1993.

Solomon, K.H. Yield related interpretations of irrigation uniformity and efficiency measurements. Irrigation Science, New York, v.5, n.3, p.161-72, 1984.

Walker, W.R. Explicit sprinkler irrigation uniformity: Efficiency model. Journal of the Irrigation and Drainage Division of ASCE, New York, v.109, n.3, p.317-32, 1979. 